\title{
Additives to the electrolyte for copper plating of through-holes in multilayer printed-circuit boards
}

\author{
V.Kh. Aleshina, (i)* N.S. Grigoryan, id N.A. Asnis, T.A. Vagramyan \\ and T.I. Kuznetsova \\ Mendeleev University of Chemical Technology of Russia, Miusskaya pl. 9, 125047 \\ Moscow, Russian Federation \\ *E-mail: aleshinavh@gmail.com
}

\begin{abstract}
As technologies are developing, the design of multilayer printed-circuit boards gets increasingly complicated, and requirements for their quality become increasingly stringent. To manufacture state-of-the-art high-accuracy printed-circuit boards with small aspect ratio ${ }^{1}$ values, copper plating electrolytes with high throwing power are required. We are developing an electrolyte for copper plating of through-holes in multilayer printed-circuit boards that enables the production of uniform bright plating both inside the holes and on the printed-circuit board surface. The effect of inhibiting, leveling, and brightening additives on the throwing power of electrolytes and copper plating distribution in the holes and on the surface of a printed-circuit board and the plating gloss have been studied. It has been found that adding polyethylene glycols to the electrolyte enhances the throwing power by $5 \%$ on average and, if the solution contains both polyethylene glycol and a leveler (a nitrogen-containing surface active agent), the throwing power increases by more than 10\%. It has been shown that if PEG 4000 polyethylene glycol is added to a sulfuric acid copper plating electrolyte together with leveling agents, methyl violet or safranine T, copper reduction is significantly inhibited (polarization is $\sim 200 \mathrm{mV}$ ), and the process polarizability increases in the entire range of current densities. It has been determined that a combination of the PEG 4000 inhibitor, Janus Green B leveling agent or polyethylenimine, and the MPS accelerating agent in the electrolyte provides bright and uniform plating both inside the holes and on the surface of printed-circuit boards.
\end{abstract}

Keywords: printed-circuit boards, copper plating electrolyte, throwing power, copper plating of printed-circuit board holes, inhibiting additives, leveling additives, brightening agent, copper electroplating.

Received: November 14, 2021. Published: November 26, 2021 doi: $\underline{10.17675 / 2305-6894-2021-10-4-18}$

\footnotetext{
1 The aspect ratio is the ratio of the diameter of the smallest metallized hole and the thickness of the printedcircuit board [1].
} 


\section{Introduction}

Printed-circuit boards are an integral part of modern devices and equipment intended for various purposes. A printed-circuit board (PCB) is a board made of a dielectric (glass-fiber laminate, paper-based laminate, etc.), on the surface and in the bulk of which conducting elements of an electronic circuit are made to connect electronic components in electric and mechanical ways [2].

Given the modern requirements for the dimensions and compactness of products, multilayer printed-circuit boards (MPCBs) enjoy the highest demand in the industry and make the major part of production. An MPCB consists of pressed-in alternating layers of a dielectric with a current-conducting pattern (CCP) applied. The electric connections between the CCPs that are located on the outer board surfaces and on the surface of inner dielectric layers are provided by metallizing the through-holes in the PCB.

Metal plating of PCB through-holes includes preparation (cleaning and conditioning, etching, and activation), chemical copper plating, and subsequent copper electroplating. These processes determine the quality of printed-circuit boards [3].

With the development of technologies, the production of high-accuracy printed-circuit boards becomes increasingly important. The PCB accuracy class is determined by the socalled aspect ratio, i.e., the ratio of the hole diameter and the board thickness. GOST (Russian national standard) 23751-86 [4] sets the ratio of the smallest hole diameter and the printedcircuit board thickness equal to 0.2. However, manufacturing capacities have been significantly enhanced since 1986, and the aspect ratio values attainable now are 0.125 , $0.100,0.083$, and less [1]. Metal plating in such holes is a challenging problem that requires advanced technologies and high performance of copper plating.

The majority of Russian PCB manufacturers currently use foreign formulations for copper plating of PCB holes, since standard solutions produced in Russia (GOST 23770-79) and their later versions are inferior to foreign-made ones in the throwing power of electrolytes, service life and stability of solutions, plating gloss, etc. The list of known disadvantages of foreign-made formulations includes high cost, necessity of warehouse stocks, and sanction risks.

It should be noted that the scant published data about foreign technologies for copper plating of PCB holes contain know-how due to which these technologies cannot be used.

In view of the above, the development of a domestic technology of copper plating of printed-circuit board holes is an important research and engineering problem. Our work attempts to find a solution to this problem.

\section{Experimental}

We prepared copper plating electrolytes using "pure" and "chemically pure" grade reagents and distilled water. The freshly made copper plating electrolyte was treated to remove impurities by passing $2 \mathrm{~A} \cdot \mathrm{h} / \mathrm{L}$ electricity at a cathodic current density of $i_{\mathrm{c}}=2 \mathrm{~A} / \mathrm{dm}^{2}$, $t=25^{\circ} \mathrm{C}$, with mechanical mixing on a magnetic stirrer at $750 \mathrm{rpm}$. 
The throwing power (TP) of the electrolyte was estimated using two methods: the Haring-Blum cell and cross-sections.

\section{Haring-Blum cell method}

The Haring-Blum cell (Figure 1) is a bath with a rectangular cross-section which contains a 5-plate copper anode and two flat copper cathodes installed at different distances from the anode [5].

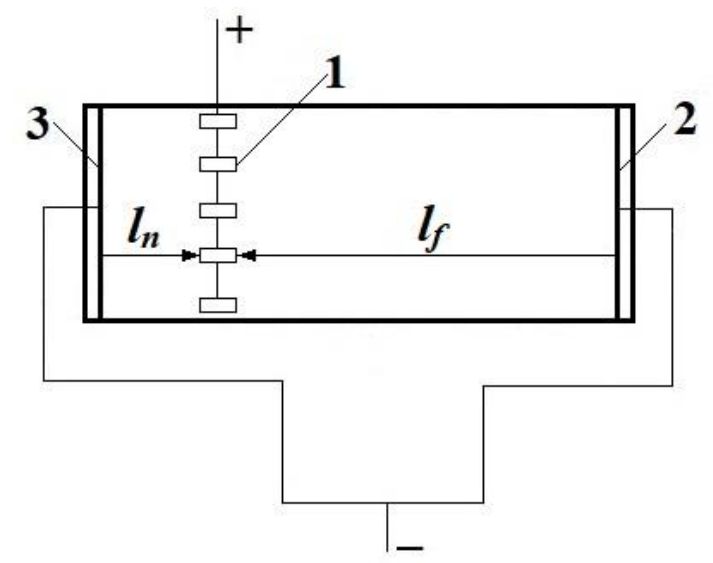

Figure 1. The Haring-Blum cell: 1 - anode; 2 - far cathode; 3 - near cathode; $l_{\mathrm{n}}$ - distance between the anode and the near cathode; $l_{\mathrm{f}}$ - distance between the anode and the far cathode [6].

Such a cell simulates the unequal accessibility of various segments of the plated surface from anodes, for example, segments of printed-circuit board holes in the case of galvanic copper plating. The near cathode is located in the Haring-Blum cell 4 times closer to the anode than the far one; therefore, the voltage drop in the second case is, according to Ohm's law, also 4 times larger. The larger the electrolyte TP, the smaller the difference in the weight gain of the near and far cathodes after electroplating, which is taken into account in the formula used to calculate $T P$ :

$$
T P=\frac{K-M}{K} \cdot 100 \%
$$

where $K=\frac{l_{\mathrm{f}}}{l_{\mathrm{n}}}$ is the initial distribution equal to the ratio of the distances between the anode and the far and near cathodes and $M=\frac{m_{\mathrm{n}}}{m_{\mathrm{f}}}$ is the secondary, actual, distribution of the metal equal to the ratio of the masses deposited on the near, $m_{\mathrm{n}}$, and far, $m_{\mathrm{f}}$, cathodes [6].

Electrolysis was carried out at $i_{\mathrm{c}}=1 \mathrm{~A} / \mathrm{dm}^{2}$ and was continued for $\tau=60 \mathrm{~min}$.

\section{Cross-section method}

In assessing the throwing power of the electrolyte by this method, test coupons were employed as plating samples. The coupons were plates of 1.5-mm-thick FR-4 film-clad 
dielectric (glass - fiber laminate, copper foil thickness $12-15 \mu \mathrm{m}$ ) with a set of holes whose diameters ranged from 0.2 to $0.8 \mathrm{~mm}$ (Figure $2 \mathrm{a}$ ). Such coupons are widely used to control the production quality in manufacturing printed-circuit boards. The plating distribution was assessed in holes with the smallest diameter $(0.2 \mathrm{~mm})$ and an aspect ratio of 0.13 .

The surface of holes in the test coupons does not conduct current; therefore, for copper plating a thin layer of chemical copper $(1-3 \mu \mathrm{m})$ was deposited at the first stage using the PERFEKTO technology currently utilized by some Russian manufacturers. Copper plating was carried out using the deposition regime currently used at plants where the reference electrolyte chosen by us is used: current density $2 \mathrm{~A} / \mathrm{dm}^{2}$; the process time was calculated with consideration for the required plating thickness $(25 \mu \mathrm{m})$. The electrolyte temperature was maintained at $25 \pm 3^{\circ} \mathrm{C}$, and the electrolyte was mechanically mixed using a magnetic stirrer $(750 \mathrm{rpm})$. Immediately prior to copper plating, the chemical copper coating was activated for $15 \mathrm{~s}$ in $10 \% \mathrm{H}_{2} \mathrm{SO}_{4}$.

To make cross-sections, after copper plating the test coupon was mounted in a bath in the orientation perpendicular to the bath bottom (section line 1 in Figure $2 b$ ). The bath was then filled with an epoxy resin with a hardener in a ratio of 2.5:1 and was slightly shaken for the resin to fill the through-holes. To harden the resin, the cross-section was maintained for 24 hours at $18-22^{\circ} \mathrm{C}$, and for the next 24 hours, in a drying cabinet at $40-70^{\circ} \mathrm{C}$. To make a cross-section, the sample was subject to 6-stage treatment with an abrasive wheel (4002000 grit) down to section line 2, the hole diameter (Figure 2b). The sample was then polished on a felt wheel using the GOI No. 2 polishing composition (fine: $74 \%$ chromium oxide, $26 \%$ binding agent, and auxiliary additives). Etching was then performed to determine the plating boundaries and remove copper sediments that emerged during grinding and polishing. The etching solution composition was: $10 \mathrm{~mL}$ of $25 \% \mathrm{NH}_{4} \mathrm{OH}, 1 \mathrm{~mL}$ of $37 \%$ $\mathrm{H}_{2} \mathrm{O}_{2}$, and $10 \mathrm{~mL}$ of distilled water [7].
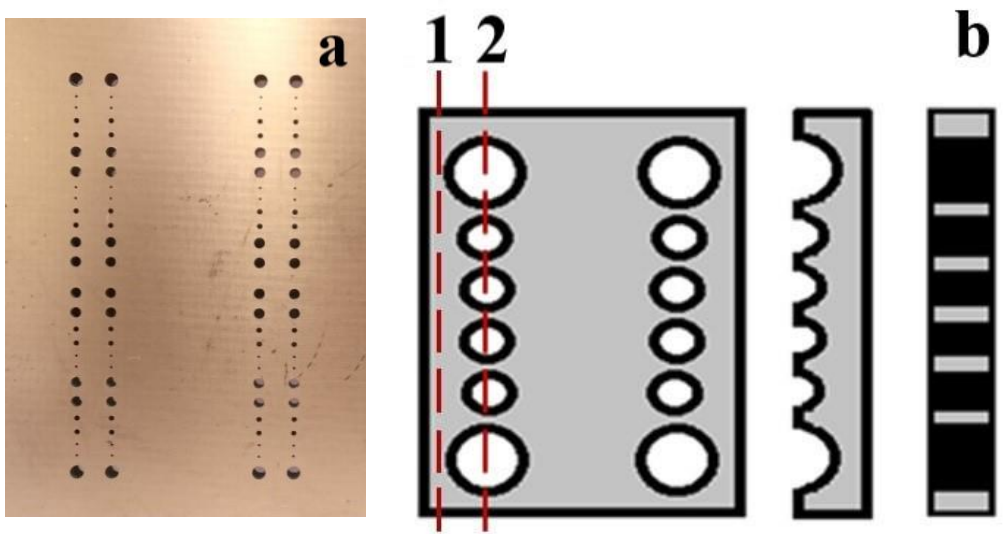

Figure 2. a) test coupon; b) test coupon cross-section, where 1 and 2 are the section lines.

The surface of the prepared cross-section was examined and its images were obtained using a LOMO RV-21 metallographic microscope and a Levenhuk M1400 PLUS digital camera under 500x magnification (Figure 3). The built-in plotting scale was used by the 
camera software to determine the plating thickness on the images obtained. Since the hole in its entirety cannot be fitted into a single frame under the selected magnification, the image of the hole was compiled using six fragments, 4 of which were located near the hole edges and 2 , in the hole center.

The coating distribution in the $\mathrm{PCB}$ holes was estimated quantitatively using the equations for $T P_{\min }$ and $T P_{\max }$ used by foreign and Russian developers and manufacturers of PCBs [8-11].

$$
\begin{gathered}
T P_{\text {min }}=\frac{\left(B_{3}+B_{4}\right) / 2}{\left(S_{1}+S_{2}+S_{3}+S_{4}\right) / 4} \cdot 100 \% \\
T P_{\max }=\frac{\left(B_{1}+B_{2}+B_{3}+B_{4}+B_{5}+B_{6}\right) / 6}{\left(S_{1}+S_{2}+S_{3}+S_{4}\right) / 4} \cdot 100 \%
\end{gathered}
$$

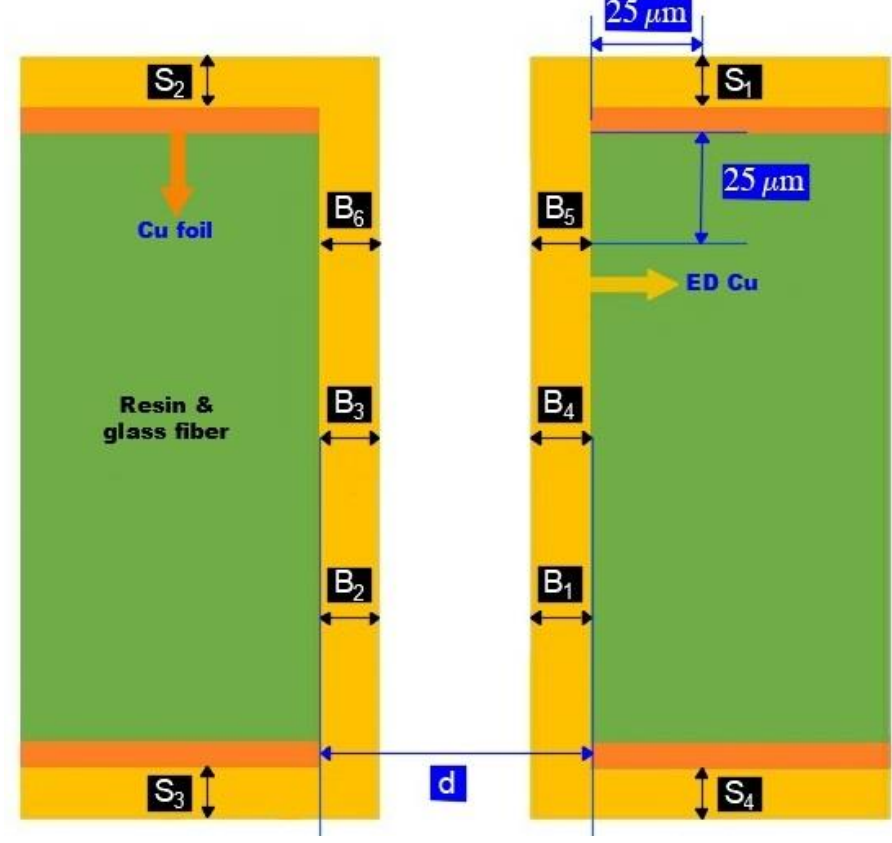

Figure 3. Schematic representation of the test coupon cross-section: $d$ is the diameter of the PCB through-hole [8].

$T P_{\min }$ reflects the coating distribution uniformity both on the board surface and inside the hole, taking into account the plating thickness at two points in the hole center $\left(B_{3}, B_{4}\right)$ and at 4 points on the PCB surface $\left(S_{1}-S_{4}\right) . T P_{\max }$, which only represents the coating distribution inside the through-hole itself, only involves the coating thickness at 6 points inside the hole $\left(B_{1}-B_{6}\right)$.

Cathodic polarization curves were recorded in potentiostatic mode using an IPC-Pro MF potentiostat (Russia) connected to an YaSE-2 three-electrode cell. A saturated silverchloride electrode was used as the reference electrode. A copper foil sample $1 \mathrm{~cm}^{2}$ in area with $10 \mu \mathrm{m}$ thick electroplated copper was used as the working electrode. All measurements were conducted at ambient temperature, $25^{\circ} \mathrm{C}$. 
The gloss of electroplated copper was measured by an Elcometer 480 gloss meter using the GU (Gloss Unit) scale. Current standards set two reference values for the gloss measurement angle of $60^{\circ}$ (which is the most universal value for measurements): $0 \mathrm{GU}$ and $1000 \mathrm{GU}$. The zero GU value corresponds to a matt surface with zero reflection, while 1000 $\mathrm{GU}$, to a black glossy surface [12]. The plating gloss was measured using flat copper-plated samples of foil-cladded FR-4 dielectric $20 \times 20 \mathrm{~mm}$ in size, no less than 5 times for each sample. The gloss of the initial copper foil on the foil-cladded dielectric was 70-85 GU.

For comparison we employed Cupracid TP3, an electrolyte for copper plating of PCB holes produced in Germany, which is used by many Russian manufacturers of PCBs.

\section{Results and Discussion}

The main requirements for a galvanic copper coating inside the holes and on the PCB surface are continuity and uniformity of the coating, including the absence of the so called "dog bone", i.e., an excessive deposit of the metal at the hole entry. In addition, the copper coating should be glossy, and the thickness of the glossy coating in the holes should be no smaller than $75-80 \%$ of that on the PCB surface [13]. Given the small aspect ratios on modern boards, a mandatory requirement for the copper plating electrolyte is its high throwing power that provides continuous and uniform plating in PCB holes.

Modern foreign-made electrolytes feature a high throwing power. For example, the throwing power of a foreign-made analog that we determined experimentally was $T P=55 \%$ (the Haring-Blum method) and $T P_{\min }=91 \%, T P_{\max }=95 \%$ (the cross-section method).

It is known that the most promising electrolytes for copper plating of PCB holes are sulfuric acid electrolytes, which contain $\mathrm{Cu}^{2+}$ and $\mathrm{H}_{2} \mathrm{SO}_{4}$ in a proportion of $1: 10, \mathrm{Cl}^{-}$ions, in some cases $\mathrm{Fe}^{2+}$ ions, and several types of functional additives [14].

As a base electrolyte, we have chosen for our study a sulfuric acid electrolyte containing (g/L): $100 \mathrm{CuSO}_{4} \cdot 5 \mathrm{H}_{2} \mathrm{O}, 200 \mathrm{H}_{2} \mathrm{SO}_{4}(96 \%)$, and $0.11 \mathrm{NaCl}$.

Preliminary studies have shown that a loose flaky coating is deposited in the absence of chloride ions in the solution, so we were unable to measure the electrolyte TP value. If chloride ions are available in the electrolyte, compact coatings are deposited; however, the TP of such an electrolyte is too small compared with that of a foreign-made analog (27\% vs $55 \%)$.

To enhance TP, we added some compounds, such as functional additives, to the base electrolyte and studied their effect on the electrolyte TP, copper coating distribution in holes and on the MPCB surface, and the plating gloss.

Foreign publications report three main types of functional additives to the electrolyte for copper plating of PCBs: inhibiting, leveling, and brightening ones (sometimes referred to as "accelerating" in literature) [15]. The concurrent presence of the additive types described above in the electrolyte provides the required uniformity and gloss of the copper coating.

It is known that an inhibiting additive is a polymeric compound whose large molecules are adsorbed on the surface to be coated and form a barrier for penetration of copper ions, as 
a result of which it inhibits copper deposition both in the holes and on the PCB surface and thus facilitates the formation of denser and finer deposits [16-18].

Non-ionogenic or cation-active surface agents that contain a charged nitrogen atom are used as levelers. It is believed that for this reason, these compounds are electrostatically adsorbed on the negatively charged cathode surface, predominantly in areas with a higher density of electric field lines, i.e., on protruding cathode parts (for example, at a hole entry). Due to the adsorption of the leveler in these areas, additional suppression occurs, which enables the plating in the lower density areas to be levelled with that in the areas with a higher density of current [19-21]. It is also known that inhibiting and leveling additives are not consumed and do not undergo chemical conversion of the metal surface [16].

We used the Haring-Blum method to examine the effect of some polymeric organic compounds and nitrogen-containing surface-active agents on the electrolyte TP. We studied polyethylene glycols, polypropylene glycols, and polyvinyl alcohol as inhibiting additives, and methyl violet (MV) (methyl violet is an organic dye that contains alkyl (primarily, methyl) derivatives of fuchsine and whose chemical formula is $\mathrm{C}_{24} \mathrm{H}_{28} \mathrm{~N}_{3} \mathrm{Cl}$ ) and safranine $\mathrm{T}$ (ST) $(3,6-$ diamino-2,7-dimethyl-10-phenylphenazynehydrochloride) is an organic basic diazyne dye, a member of the safranine class, whose chemical formula is $\mathrm{C}_{20} \mathrm{H}_{19} \mathrm{~N}_{4} \mathrm{Cl}$ ) as leveling agents $[22,23]$. It has been found that polyethylene glycols (PEGs) most favorably affect the throwing power of the sulfuric acid copper plating electrolyte. Our studies have shown that adding PEG (with molecular masses of 400, 1000, 1500, 4000, or $8000 \mathrm{~g} / \mathrm{mol}$ ) to the electrolyte enhances $T P$ by $5 \%$ on average; however, if the solution contains both PEG and a leveler, whether methyl violate or safranine T, TP increases by more than $10 \%$ (Figure $4 \mathrm{a}$ and $4 b)$.

Although the electrolyte that contains PEG 400 exhibits the highest $T P$ at some concentration, we believe that PEG 4000 is more promising as an inhibitor if combined with the methyl violet leveler, inasmuch as it provides higher $T P$ values in a broader range of concentrations, which is more suitable for industrial production (Figure 4a). PEG 4000 was also found to be most efficient in combination with safranine T (Figure $4 \mathrm{~b}$ ).

Polarization studies have shown that suppression of copper reduction in the presence of PEG 4000 is comparable to that of a foreign-made analog (Suppressor TP3): in both cases, the polarization curve is shifted to negative values approximately by $100-200 \mathrm{mV}$ (curves 2 and 3 in Figure 5a). The process polarizability also increases by a comparable value for both compounds in the entire range of current densities. The effect of the levelers is manifested in a small shift of potentials to negative values $(100-150 \mathrm{mV})$ and a slight increase in polarization (curves 4-6 in Figure 5a). 

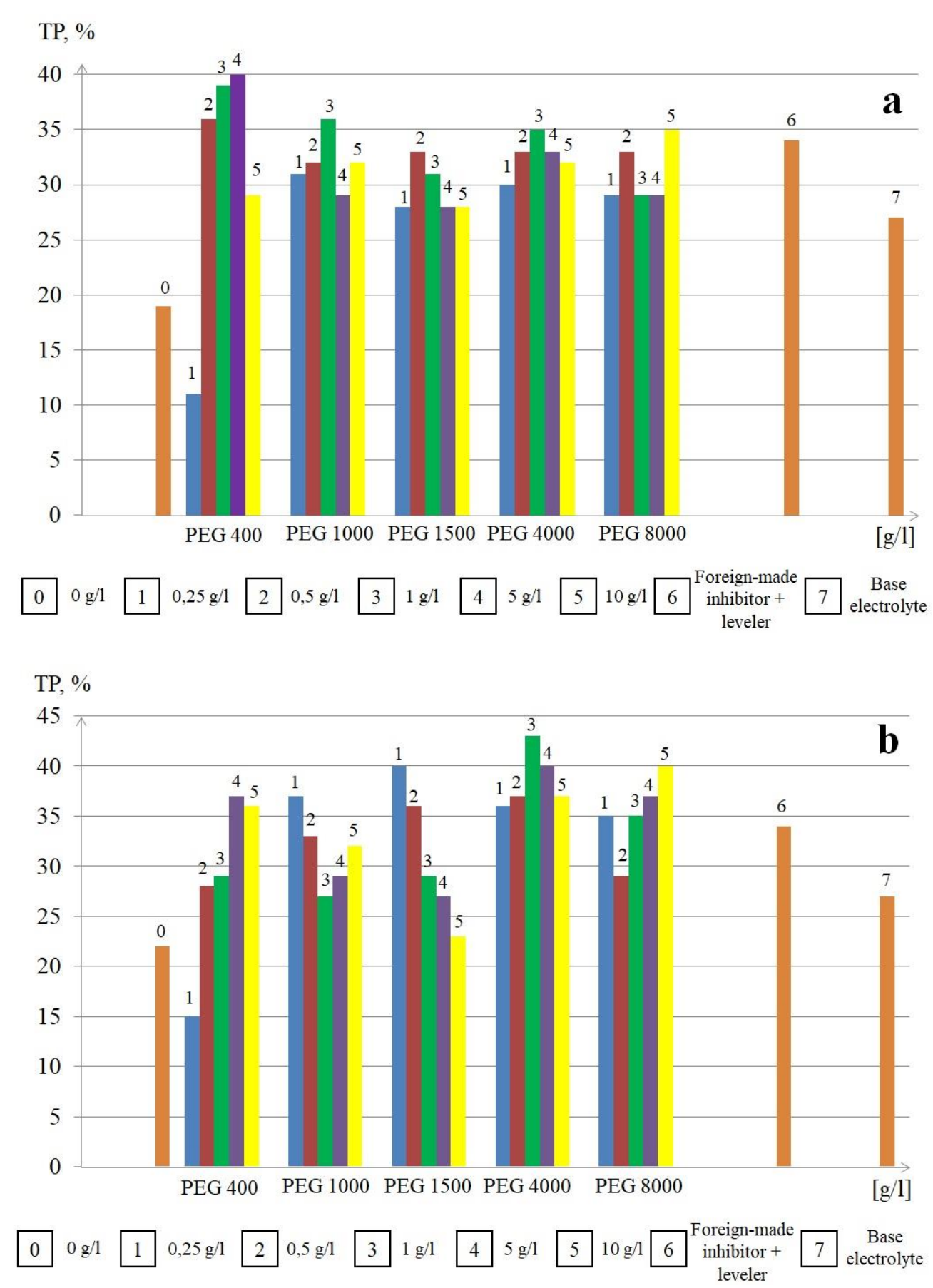

Figure 4. Electrolyte $T P$ vs molecular mass and PEG concentration in the presence of a leveler $(0.003 \mathrm{~g} / \mathrm{L})$ : a) methyl violet; b) safranine $\mathrm{T}$.

Taking the results obtained into account, polyethylene glycol with a molecular mass of 4000 was selected as the inhibitor for further studies. The dependence of the $T P$ on the leveler concentration in the electrolyte was examined at the optimal content of PEG 4000 in the electrolyte $(1.0 \mathrm{~g} / \mathrm{L})$. With consideration for published data, such compounds as Janus Green B (JGB) (2-diethylamine-3,6-dimethyl-9-phenylphenazonium-7-azo-4'-dimethylaniline chloride) is an organic dye, a diazotized safranine, the chemical formula of which is 
$\mathrm{C}_{32} \mathrm{H}_{35} \mathrm{~N}_{6} \mathrm{Cl}$ ), brilliant green (BG) (tetraethyl-4,4-diaminetriphenylmethane oxalate) is a synthetic aniline dye of triphenylmethane series, the chemical formula of which is $\mathrm{C}_{27} \mathrm{H}_{34} \mathrm{~N}_{2} \mathrm{O}_{4} \mathrm{~S}$ ), and polyethyleneimine (PEI) (polyethyleneimine $M_{\mathrm{w}}=25000 \mathrm{~g} / \mathrm{mol}$ $\left(\left[\mathrm{CH}_{2} \mathrm{CH}_{2} \mathrm{NH}\right]_{n}\right)$ is a polymer with a repeating link consisting of an amino group and a twocarbon aliphatic spacer $\left.\mathrm{CH}_{2} \mathrm{CH}_{2}\right)[22,24,25]$ were studied along with methyl violet and safranine $\mathrm{T}$.
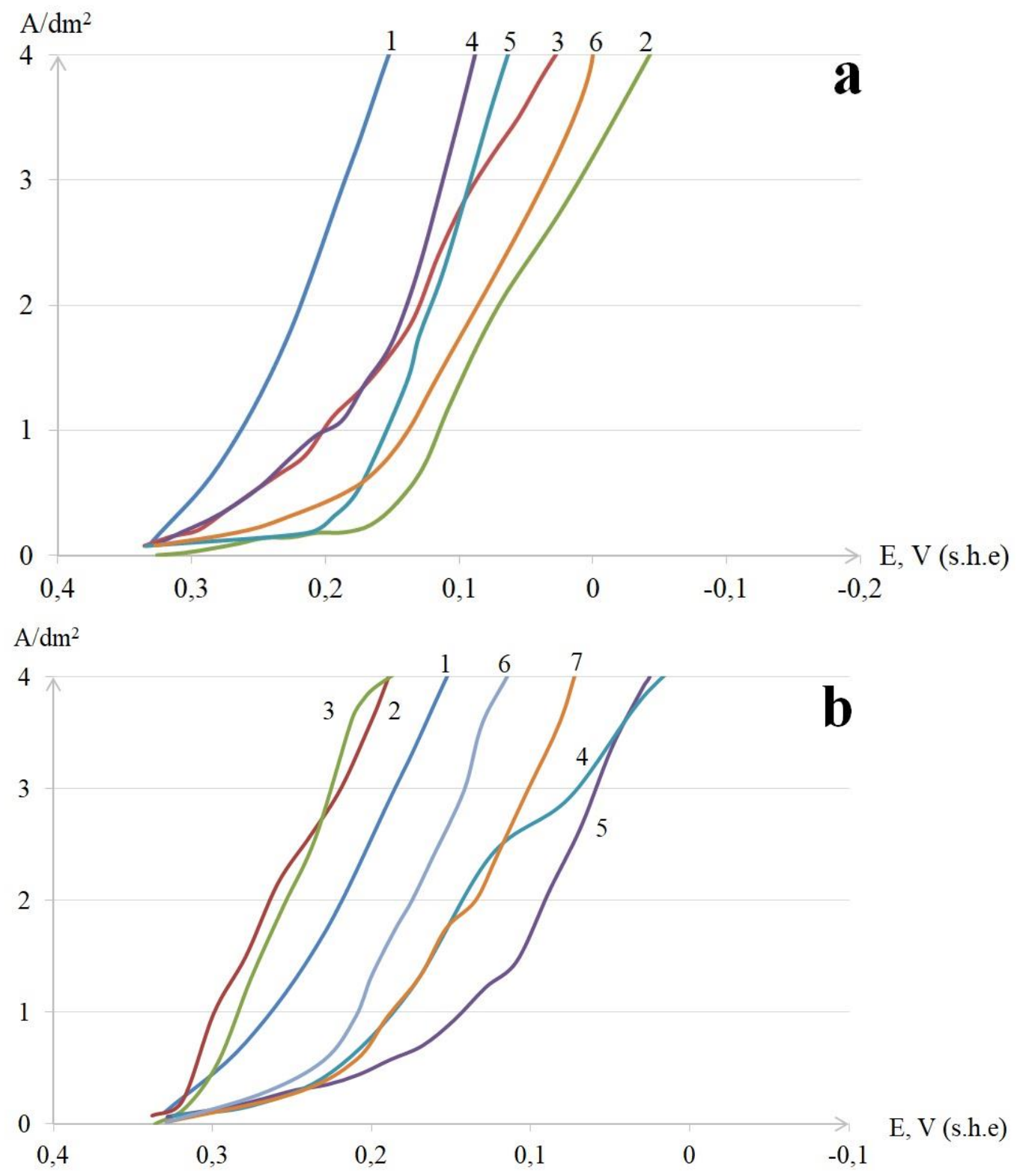

Figure 5. Polarization curves of copper reduction in the solution: a) 1. Base electrolyte; $2.1+$ foreign-made inhibitor; 3. $1+$ PEG 4000; $4.1+$ foreign-made leveler; $5.1+$ safranine T; 6.1 + methyl violet; b) 1. Base electrolyte; 2.1 + foreign-made brightening agent; $3.1+$ MPS; 4 . $1+$ foreign-made inhibitor and leveler; 5. 1 + PEG 4000 + PEI; 6. foreign-made electrolyte; 7 . $1+$ PEG $4000+$ PEI + MPS. 
The data displayed in Figure 6 show that the largest $T P$ values in the entire examined concentration range are attained if the following substances are used as the levelers: JGB, PEI, and BG.

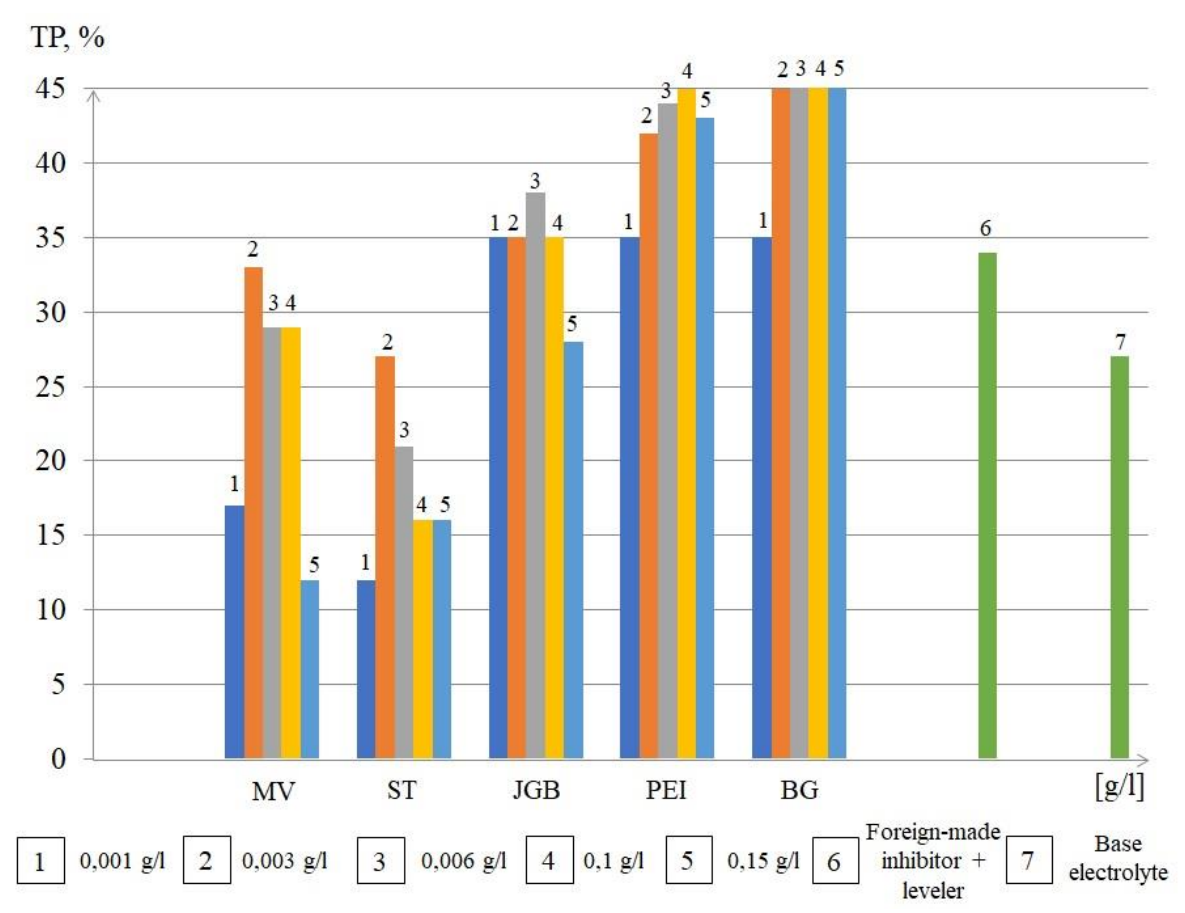

Figure 6. Effect of the nature and concentration of the leveling additive on the electrolyte $T P$ in the presence of PEG $4000(1 \mathrm{~g} / \mathrm{L})$.

The TP values correlate with the images of the PCB hole cross-section displayed in Figure 7, which were obtained using an optical metallographic microscope. Table 3 presents the values of $T P_{\min }$ and $T P_{\max }$ calculated using Eqs. (2) and (3).

It can be seen that the best coating distribution in the holes and on the board surface is attained in the electrolyte containing PEG 4000 if Janus Green B, brilliant green, or polyethylenimine is used as the leveler. Addition of these compounds to the electrolyte made it possible to improve the coating distribution significantly; however, the ratio of the plating thicknesses inside the holes and on the test coupon surface does not comply with modern requirements, according to which the plating thickness inside the hole should not be significantly smaller than that on the PCB surface: the $T P_{\min }$ value should be no less than $75-80 \%$.

To improve the coating distribution, yet another functional substance, an accelerating (brightening) agent, is added to copper plating electrolytes. Sulfur-containing compounds such as bis(3-sulfopropyl)disulfide (SPS) or its reduced monomer, 3-mercaptopropyl sulfonate (MPS), and others were reported in publications as accelerating (brightening) agents [16]. 


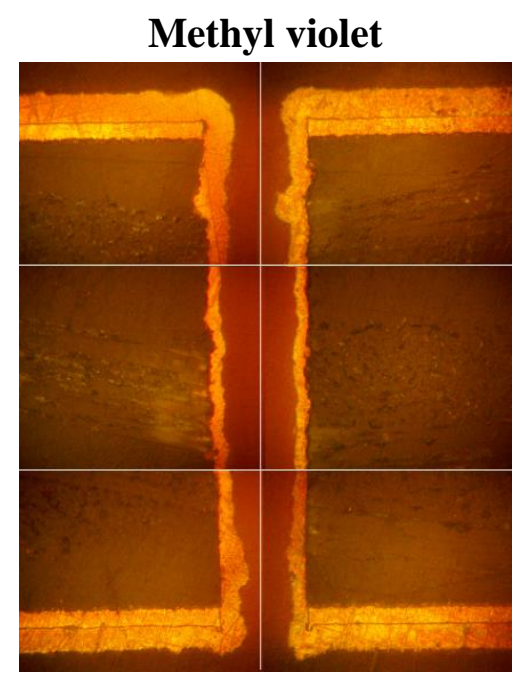

Brilliant green

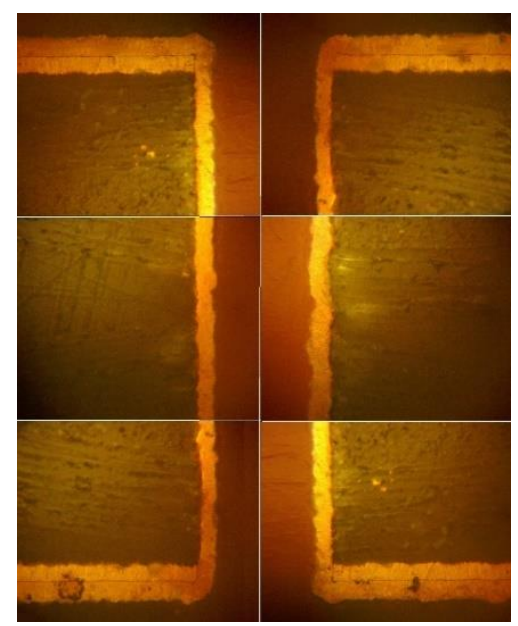

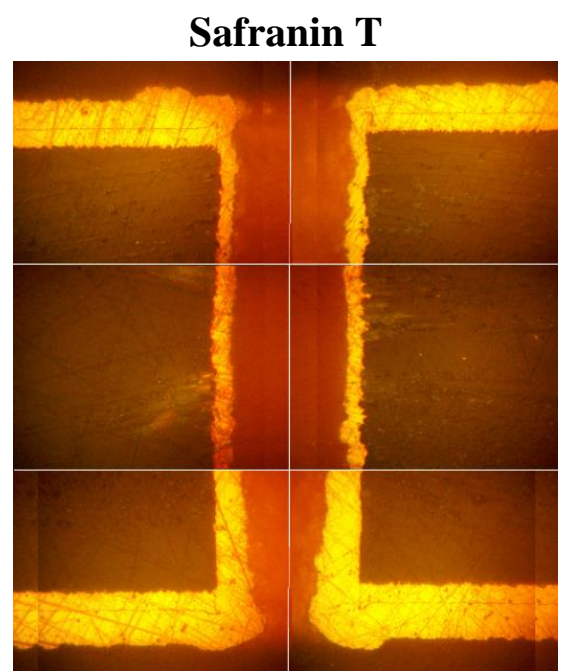

Polyethylenimine

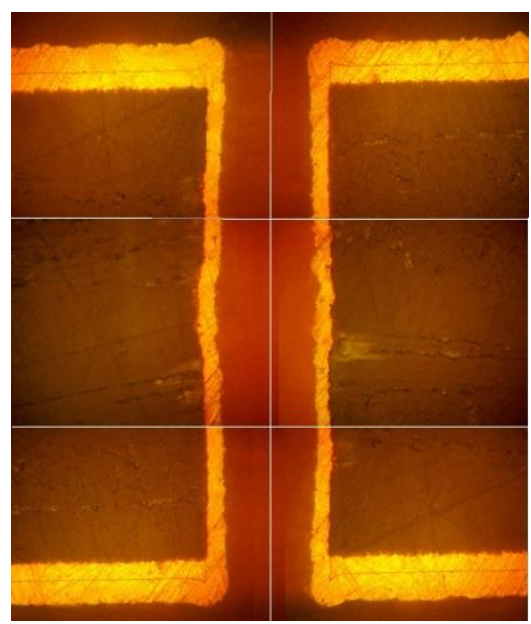

Janus Green B

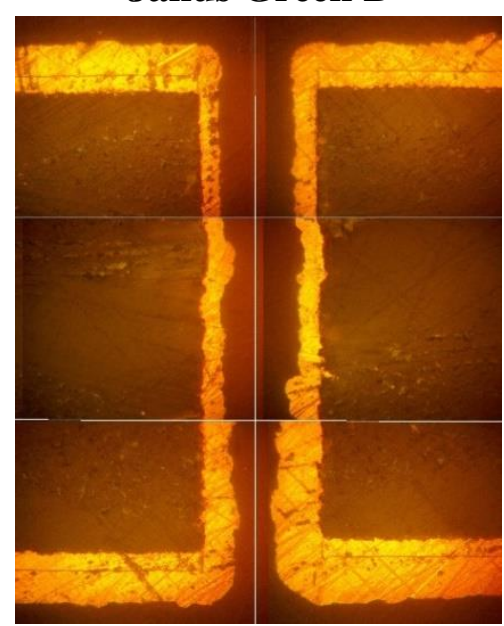

Foreign-made inhibitor + leveler

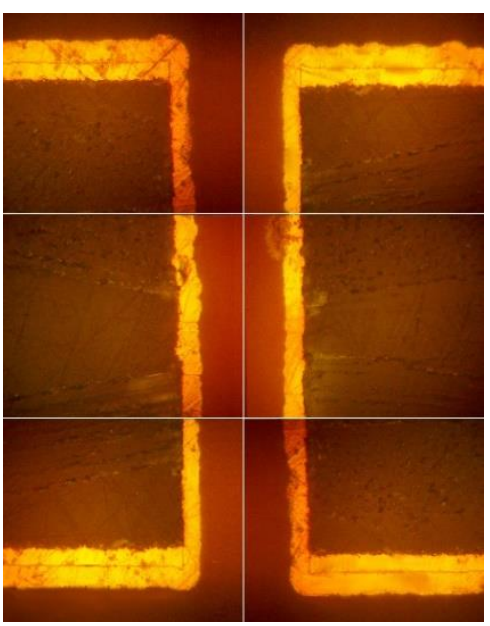

Figure 7. Images of cross-sections of test coupons with holes $0.2 \mathrm{~mm}$ in diameter (500x) with a copper coating obtained in an electrolyte containing PEG $4000(1 \mathrm{~g} / \mathrm{L})$ and a leveler $(0.006 \mathrm{~g} / \mathrm{L})$.

Table 1. Coating distribution in the holes and on the PCB surface.

\begin{tabular}{cccccc}
\hline No. & Electrolyte & $\boldsymbol{T P}_{\mathbf{m i n}}, \boldsymbol{\%}$ & $\boldsymbol{T P}_{\mathbf{m a x}}, \boldsymbol{\%}$ & $\boldsymbol{\delta}_{-}^{*}, \boldsymbol{\mu m}$ & $\boldsymbol{\delta}_{\|}^{*}, \boldsymbol{\mu m}$ \\
\hline 1. & Base electrolyte & 47 & 76 & 23 & 11 \\
2. & 1 + PEG 4000 + methyl violet & 48 & 87 & 21 & 10 \\
3. & 1 + PEG 4000 + safranine T & 59 & 58 & 27 & 16 \\
4. & 1 + PEG 4000 + Janus Green B & 68 & 60 & 28 & 19 \\
5. & 1 + PEG 4000 + brilliant green & 64 & 117 & 24 & 15 \\
6. & 1 + PEG 4000 + polyethylenimine & 63 & 70 & 25 & 16 \\
\hline
\end{tabular}

$* \delta_{-}$is the coating thickness on a test coupon surface; $\delta_{\|}$is the coating thickness inside a hole in a test coupon. 
It is assumed that an accelerating agent concentrates on the profile segments located far from the anode and thus rises or displaces the adsorbed inhibitor from the surface, and as a result, ensures a higher rate of copper deposition on these surface areas [26]. In the authors' opinion, the assumed mechanism by which the accelerating agent reactivates the surface involves the removal of the inhibitor from a surface microindent either by displacing it (competitive adsorption) or by breaking the inhibitor-surface bonds [16].

We studied in this work the option to use the following compounds of the thiol or sulfonic acid class as the accelerating agents: MPS, UPS, ${ }^{2} \mathrm{MSA},{ }^{3} p$-TSA, ${ }^{4}$ and $m$-NBS ${ }^{5}[27-$ 29]. For each additive, measurements were made at 5 concentrations ranging from 0.001 to $0.1 \mathrm{~g} / \mathrm{L}$. Polarization studies have shown that MPS alone affects copper reduction as a depolarizer (curves 2 and 3 in Figure 5b).

The results presented in Table 2 also indicate that the most uniform coating distribution in the holes and on the PCB surface is attained if PEG, PEI (or JGB), or MPS is present in the electrolyte.

It has been found as well that adding MPS along with PEG and PEI (or JGB) to the electrolyte provides plating with the largest gloss value (315-350 GU), which is comparable with that obtained using a foreign-made analog (Table 3 ).

Table 2. Coating distribution in the holes and on the PCB surface.

\begin{tabular}{cccccc}
\hline No. & Electrolyte & $\boldsymbol{T P}_{\mathbf{m i n}, \boldsymbol{\%}}$ & $\boldsymbol{T P}_{\mathbf{m a x}}, \boldsymbol{\%}$ & $\boldsymbol{\delta}_{-}^{*}, \boldsymbol{\mu m}$ & $\boldsymbol{\delta}_{\|,}^{*}, \boldsymbol{\mu m}$ \\
\hline 1 & Base electrolyte & 47 & 76 & 23 & 11 \\
2 & 1 + PEG 4000 + JGB + MPS & 82 & 95 & 25 & 21 \\
3 & 1 + PEG 4000 + PEI + MPS & 88 & 97 & 23 & 20 \\
4 & 1 + PEG 4000 + PEI + UPS & 65 & 75 & 22 & 14 \\
5 & 1 + PEG 4000 + PEI + MSA & 60 & 79 & 24 & 14 \\
6 & 1 + PEG 4000 + PEI + p-TSA & 59 & 65 & 22 & 13 \\
7 & 1 + PEG 4000 + PEI + m-NBS & 71 & 73 & 23 & 16 \\
8 & Foreign-made electrolyte & 91 & 95 & 22 & 20 \\
\hline
\end{tabular}

${ }^{2}$ UPS - 3-(aminoiminomethyl)-thio)-1-propanesulfonic acid.

${ }^{3}$ MSA - methanesulfonic acid.

${ }^{4} p$-TSA - para-toluenesulfonic acid.

${ }^{5} \boldsymbol{m}$-NBS - Na salt of meta-nitrobenzenesulfonic acid. 
Table 3. Dependence of coating gloss (GU) on the nature and concentration of leveling and accelerating agents.

MPS concentration, $\mathrm{g} / \mathrm{L}$

Foreign-made analog

\begin{tabular}{cccccc}
\hline JGB concentration, g/L & 0.001 & 0.005 & 0.01 & 0.05 & 0.1 \\
\hline $\mathbf{0 . 0 0 1}$ & 2 & 3 & 4 & 7 & 7 \\
$\mathbf{0 . 0 0 3}$ & 330 & 340 & 20 & 4 & 3 \\
$\mathbf{0 . 0 0 6}$ & 315 & 350 & 7 & 3 & 2 \\
$\mathbf{0 . 0 1 0}$ & 20 & 35 & 13 & 4 & 7 \\
$\mathbf{0 . 0 1 5}$ & 5 & 4 & 3 & 3 & 2 \\
\hline PEI concentration, g/L & 0.001 & 0.005 & 0.01 & 0.05 & 0.1 \\
\hline $\mathbf{0 . 0 0 1}$ & 6 & 13 & 10 & 9 & 9 \\
$\mathbf{0 . 0 0 3}$ & 320 & 348 & 21 & 8 & 8 \\
$\mathbf{0 . 0 0 6}$ & 351 & 376 & 91 & 8 & 9 \\
$\mathbf{0 . 0 1 0}$ & 15 & 27 & 14 & 5 & 6 \\
$\mathbf{0 . 0 1 5}$ & 6 & 12 & 10 & 9 & 7 \\
\hline
\end{tabular}

Figure 8 shows images of plating cross-sections obtained using a combination of PEG 4000 inhibitor, Janus Green B or polyethylenimine leveler, and MPS accelerating agent in the electrolyte (at the concentrations displayed in a frame). It is evident that the uniformity of the coating in the holes and on the test coupon surface provided by the electrolyte is comparable to that of the foreign-made analog.
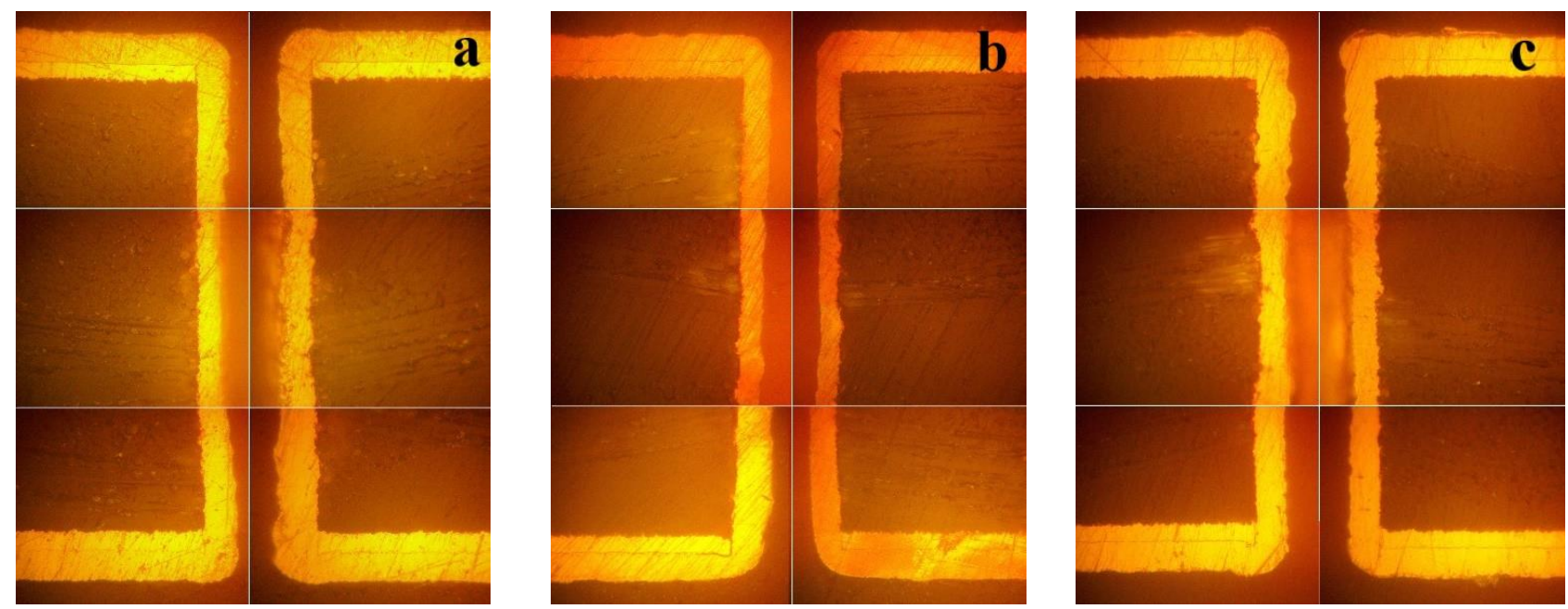

Figure 8. Images of cross-sections of test coupons with holes $0.2 \mathrm{~mm}$ in diameter $(500 \mathrm{x})$ with a copper coating obtained in the electrolyte containing (g/L): a) 1 PEG 4000; $0.006 \mathrm{JGB}$; 0.005 MPS; b) 1 PEG 4000; 0.006 PEI; 0.005 MPS; c) foreign-made electrolyte. 


\section{Conclusions}

1. It has been shown that if polyethylene glycol PEG 4000 combined with a nitrogencontaining surface-active agent, methyl violet or safranine $\mathrm{T}$, is added to a sulfuric-acid copper plating electrolyte, copper reduction is inhibited significantly (polarization is $\sim 200 \mathrm{mV}$ ), and the process polarizability increases in the entire range of current densities.

2. It has been found that if PEG 4000 inhibitor and a leveler, either methyl violet or safranine $\mathrm{T}$, are added, the $T P$ value increases by more than $10 \%$.

3. It has been found that if MPS (along with PEG and PEI or Janus Green B) is added to the electrolyte, a coating with the largest gloss value can be obtained (315-350 GU), which is comparable with that provided by a foreign-made analog.

4. A domestic electrolyte for copper plating of through-holes in MPCBs has been developed that contains $(\mathrm{g} / \mathrm{L}): 100 \mathrm{CuSO}_{4} \cdot 5 \mathrm{H}_{2} \mathrm{O} ; 200 \mathrm{H}_{2} \mathrm{SO}_{4}(96 \%) ; 0.11 \mathrm{NaCl} ; 1 \mathrm{PEG} 4000 ; 0.003-$ 0.006 Janus Green B or 0.003-0.006 polyethylenimine and 0.001-0.005 MPS. This electrolyte makes it possible to obtain at a cathodic current density $i_{\mathrm{c}}=2 \mathrm{~A} / \mathrm{dm}^{2}, t=25^{\circ} \mathrm{C}$ and with mechanical mixing by a magnetic stirrer a coating, both inside the holes and on the MPCB surface, whose uniformity and gloss are comparable to those provided by a foreign-made analog.

\section{Acknowledgements}

This work was supported by the Mendeleev University of Chemical Technology of Russia, Project Number X-2020-027.

\section{References}

1. A. Chernyshov, Accuracy classes of printed circuit boards and modern technologies, Pechatnyi montazh, 2009, no. 6, 18-21 (in Russian).

2. A.N. Gormakov and N.A. Voronina, Design and technology of electronic devices. Printed circuit boards: Tutorial, Tomsk, Izd. TPU, 2006, 164 pp. (in Russian).

3. A.M. Medvedev, Technology of manufacturing printed circuit boards, Moscow, Tekhnosfera, 2005, 360 pp. (in Russian).

4. GOST (State Standard) no. 23.751-86, Printed circuit boards. Basic parameters of structure, Moscow, Izd. Standartov, 1988, 7 pp. (in Russian).

5. N.S. Grigoryan, A.A. Abrashov, D.V. Mazurova and T.A. Vagramyan, Protective metal and conversion coatings: laboratory course, $2^{\text {nd }}$ Revised edition, Moscow, MUCTR, 2017, 176 pp. (in Russian).

6. A.M. Yampol'skij and V.A. Il'in, Brief electroplater's reference book, $3^{\text {rd }}$ Revised edition, Leningrad, Mashinostroenie, Leningr. otd-nie, 1981, 269 pp. (in Russian).

7. I. Anchevskij and A. Medvedev, Metallographic analysis of multilayer printed boards, Tekhnologii v elektronnoj promyshlennosti, 2005, no. 2, 35-37 (in Russian). 
8. T.-C. Chen, Y.-L. Tsai, C.-F. Hsu, W.-P. Dow and Y. Hashimoto, Effects of brighteners in a copper plating bath on throwing power and thermal reliability of plated throughholes, Electrochim. Acta, 2016, 212, 572-582. doi: 10.1016/j.electacta.2016.07.007

9. M. Nikolova, J. Watkowski, D. Desalvo and R. Blake, High-temperature acid copper process for plating through-holes, Met. Finish., 2009, 3, 17-20. doi: 10.1016/S0026$\underline{0576(09) 00013-0}$

10. M. Nikolova, C. Rodriguez, W. Bowerman, J. Watkowski and K. Feng, Innovatve acid copper process for simultaneously filling vias and plating through-holes, 2017 12th International Microsystems, Packaging, Assembly and Circuits Technology Conference (IMPACT), 2017, 107-110. doi: 10.1109/IMPACT.2017.8255964

11. W. Wiedmann, K. Bartz, R. Freund, P. Meeh, J. Weckenmann and M. Sörensen, Regeneration of acid copper pulse plating baths in PCB production using UV recycling, Prod. Leiterplatten Syst., 2006, no. 7. 1-9.

12. A.A. Abrashov, N.S. Grigoryan, T.A. Vagramyan and K.N. Smirnov, Methods for control and testing of electrochemical and conversion coatings: Tutorial, Moscow, MUCTR, 2016, 212 pp. (in Russian).

13. GOST (State Standard) no. 55693-2013, Rigid printed boards. Technical requirements, Moscow, Izd. Standartov, 2014, 62 pp. (in Russian).

14. L.A. Brusnicyna and E.I. Stepanovskih, Technology of production of printed boards Tekhnologiya izgotovleniya pechatnyh plat: Tutorial, Ekaterinburg, Izd-vo Ural. Univ., 2015, 200 pp. (in Russian).

15. Acidic aqueous composition for electrolytic copper plating: WO Patent, 2018/033461 $\mathrm{Al}, 25 \mathrm{D} 3 / 38,2018$.

16. K. Kondo, R.N. Akolkar, D.P. Barkey and M. Yokoi, Copper electrodeposition for nanofabrication of electronics devices, Nanostructure Science and Technology, Springer, New York, Heidelberg, Dordrecht, London, 2014, vol. 171, p. 282. doi: 10.1007/978-1-4614-9176-7

17. Method of electroplating uniform copper layer on the edge and walls of though holes of a substrate: EP Patent, 2465976 A1, C25D3/38, 2012.

18. Electrolytic copper plating bath composition and a method for their use: WO Patent, 2016/169952 Al, C25D3/38, 2016.

19. W. Dow, C. Li, M. Lin and G. Su, Copper fill of microvia using a thiol-modified Cu seed layer and various levelers, J. Electrochem. Soc., 2009, 156, 314-318. doi: $\underline{10.1149 / 1.3147273}$

20. Y. Li, W. Wang and Y. Li, Adsorption behavior and related mechanism of Janus Green B during copper via-filling process, J. Electrochem. Soc., 2009, 156, 119-220. doi: 10.1149/1.3071603

21. C. Wang, M. An, P. Yang and J. Zhang, Prediction of a new leveler (N-butyl-methyl piperidinium bromide) for through-hole electroplating using molecular dynamics simulations, Electrochem. Commun., 2012, 18, 104-110. doi: 10.1016/j.elecom.2012.02.028 
22. C. Wang, J. Zhang, P. Yang and M. An, Electrochemical behaviors of Janus Green B in through-hole copper electroplating: An insight by experiment and density functional theory calculation using Safranine T as a comparison, Electrochim. Acta, 2013, 92, 356364. doi: $10.1016 /$ j.electacta.2013.01.064

23. Verfahren zur Kupferplattierung: EP Patent, 2537962A1, C25D3/38, 2012.

24. Z. Lai, S. Wang, C. Wang, Y. Hong, Y. Chen, H. Zhang, G. Zhou, W. He, K. Ai and Y. Peng, Computational analysis and experimental evidence of two typical levelers for acid copper electroplating, Electrochim. Acta, 2018, 273, 318-326. doi: 10.1016/j.electacta.2018.04.062

25. A.A. Tyul'kova, Yu.S. Bobrova and O.N. Smirnova, Effect of organic additives on the filling of blind vias in the manufacture of electronic devices, Gal'vanotekh. Obrab. Poverkhn., 2016, 24, no. 4, 61-67 (in Russian).

26. Z. Li, B. Tan, M. Shi, J. Luo, Z. Hao, J. He, G.-N. Yang and C. Cui, Bis-(sodium sulfoethyl)-disulfide: A promising accelerator for super-conformal copper electrodeposition with wide operating concentration ranges, J. Electrochem. Soc., 2020, 167, 042508. doi: $\underline{10.1149 / 1945-7111 / a b 7 b 85}$

27. I. Volov and A.C. West, Interaction between SPS and MPS in the presence of ferrous and ferric ions, J. Electrochem. Soc., 2011, 158, 456-461.

28. M. Ning, W. He, X. Tang, Z. Tao, X. He, L. Xiang, Y. Hu, X. Su and S. Cheng, Research on the effect of inorganic components on brightener in horizontal pulse plating solution by Cyclic Voltammetric Stripping method, 2012 7th International Microsystems, Packaging, Assembly and Circuits Technology Conference (IMPACT), 2012, 333-336. doi: 10.1109/IMPACT.2012.6420216

29. T.-C. Chen, Y.-L. Tsay, C.-F. Hsu, W.-P. Dow and Y. Hashimoto, Effects of brighteners in a copper plating bath on throwing power and thermal reliability of plated throughholes, Electrochim. Acta, 2016, 212, 572-582. doi: 10.1016/j.electacta.2016.07.007 